\title{
Role of Emotional Maturity on Stress among Undergraduate Students
}

\author{
Masaud Ansari ${ }_{1}$
}

\section{ABSTRACT:}

An attempt was made to study impact of Emotional Maturity on Stress among Undergraduate students. The sample of the study was selected by using the purposive sampling technique. The sample consisted of 150; participant's age range was 18 to 20 years. Emotional Maturity Scale constructed by Yashvir Singh and Mahesh Bhargava (2005) and Stress questionnaire developed by Latha and Satish (1997), was used for data collection. The Simple Linear Regression was used to determine the Correlation as well as Coefficient between Emotional Maturity and Stress among undergraduate students. The findings of the study revealed that a significant impact of Emotional Maturity was found on Stress among undergraduate students. There was also found significant negative correlation between Emotional Maturity and Stress. The result revealed that, when emotional maturity increases stress decreases and when emotional maturity decreases stress increases.

Keywords: Emotional Maturity, Stress and undergraduate Students.

\section{INTRODUCTION:}

To think affirmative, to live a joyful life, to carry out any event of life, to make particular judgment or to deal with the problems, Emotional Maturity is important. Concerning all these things, this study was carried out on undergraduate Students. Literature indicates the dearth of information about impact of emotional maturity on particularly stress among undergraduate students. Therefore the present study is an attempt in this direction. The objective of the present study: To see the role of emotional maturity on the stress among undergraduate.

\section{Emotional Maturity}

Emotional maturity can be understood in terms of ability of self control which in turn is a result of thinking and learning. According to Chamberlain (1960), an emotionally matured person is one whose emotional life is well under control.

In psychology, maturity is the ability to respond to the environment in an appropriate manner. This response is generally learned rather than instinctive. Maturity also encompasses being aware of the correct time and place to behave and knowing when to act, according to the circumstances and the culture of the society one lives in. In an article Anjali (2005) reports that conflicts in family, unbalanced nutrition, less of exercise, separated father and mother, extreme protection and punishment, lack of proper sexual education and hormonal changes are responsible for the stress.

\footnotetext{
${ }^{1}$ Research Scholar, Department of Psychology, Aligarh Muslim University, Aligarh.
} 
The emotional maturity consists of five dimensions viz. emotional stability, emotional progression, social adjustment, personality integration and independence.

\section{Emotional stability}

It refers to the characteristics of a person that does not allow him to react excessively or given to swings in mood or marked changes in any emotive situation. The emotionally stable person is able to do what is required of him in any given situation. Contrary to it emotional instability is a tendency to quick changing and unreliable responses and is a factor representing syndrome of irritability, stubbornness and temper tantrums, lack of capacity to dispose of problems and seek help for one's day to day problems (Yashvir Singh and Mahesh Bhargava 2005a).

\section{Emotional Progression}

Emotional progression is the characteristic of a person that refers to a feeling of adequate advancement and going vitality of emotions in relation to the environment to ensure a positive thinking imbued with righteousness and contentment whereas, emotional regression is also a broad group of factors representing such syndromes as feeling of inferiority, restlessness, hostility, aggressiveness and self-centeredness (Yashvir Singh and Mahesh Bhargava 2005b).

\section{Social Adjustment}

Social adjustment refers to a process of interaction between the needs of a person and demands of the social environment in any given situation, so that they can maintain and adapt a desired relationship with environment. Therefore, it may be described as a person's harmonious relationship with his social world whereas, socially maladjusted person shows lack of social adaptability should hatred, seductive but boasting, but liar and shirker (Yashvir Singh and Mahesh Bhargava 2005c).

\section{Personality Integration}

Personality integration is the process of firmly unifying the diverse elements of an individual's motives and dynamic tendencies, resulting in harmonious coactions and de-escalation of the inner conflict in the undaunted expression of behavior (English and English, 1958). The disintegrated personality includes all those symptoms like reaction, phobias formation, rationalization, pessimism, immorality etc. Such a person suffers from inferiorities and hence reacts to environment through aggressiveness, destruction, and has distorted sense of reality (Yashvir Singh and Mahesh Bhargava 2005d).

\section{Independence}

Independence is the capacity of a person's attitudinal tendency to be self reliant or of resistance to control by others where, he can take his decisions by his own judgment based on facts by utilizing his intellectual and creative potentialities. He should never like to show any habitual reliance upon another person in making his decisions or carrying out difficult actions. A dependent person shows parasitic dependence on other is erotic and lacks 'objective interests'. People think of him an unreliable person (Yashvir Singh and Mahesh Bhargava 2005e). 


\section{Stress}

Stress is defined as the state of psychological upset or disequilibrium in the human beings caused by frustration, conflicts and other internal as well as external strains and pressures (Mangal, 1984).

Geeta, \& Vijayalaxmi, (2006) reported that adolescents with high emotional maturity have better ability of managing, directing and controlling themselves in each and every action thus results in their high self confidence. Stress Intervention is broken down into three steps: primary, secondary, tertiary. Primary deals with eliminating the stressors all together. Secondary deals with detecting stress and figuring out ways to cope with it and improving stress management skills. Finally, tertiary deals with recovery and rehabbing the stress all together. These three steps are usually the most effective way to deal with stress not just in the workplace, but overall. For the managing above mentioned stress patterns individuals are needed to be emotionally mature.

\section{OBJECTIVES:}

1. To study the impact of emotional maturity on stress among undergraduate students.

2. To study the correlation between different dimensions of emotional maturity and stress among undergraduate students.

\section{RESEARCH QUESTIONS:}

1. Is there any impact of emotional maturity on stress among undergraduate students?

2. Is there any relationship between different dimensions of emotional maturity and stress among undergraduate students?

\section{METHOD}

\section{Sample}

The sample of the study consisted of 150 undergraduate students, selected from Aligarh Muslim University, Aligarh. A purposive sampling technique was used to select the participants of the study.

\section{Tools}

\section{Emotional Maturity Scale}

Emotional Maturity Scale constructed by Yashvir Singh and Mahesh Bhargava (2005) was used in the present study. The scale consists of 48 items with five dimensions viz. emotional stability with 10 items, emotional progression with 10 items, social adjustment with 10 items, personality integration with 10 items and independence with 8 items. The reliability of the test by product moment correlation was 0.75 . The internal consistency for emotional stability was 0.75, emotional progression was 0.63 , social adjustment was 0.58 , personality integration was 0.86 and independence was 0.42 respectively and the concurrent validity of the total test was 0.64 as given in the manual. 


\section{Stress Questionnaire}

The Stress questionnaire developed by Latha and Satish (1997) consists of 52 items arranged from mild stress (least affecting the everyday affairs), moderate to severe stress (which affects the adjustment and efficiency of the individual). This lists the life experiences based on the amount of change or adjustments one has to make to life rather than the undesirability of events themselves. The item reliability value of the questionnaire was 0.86 , the reliability of the test was found to be 0.96 and the content validity was 0.86 as mentioned in the manual of the questionnaire.

\section{PROCEDURE}

The scales were applied on the undergraduate students individually, before distributing the respective measures good rapport was established and proper instructions were given to the participants and also ensured for confidentiality; after that, questionnaires were given, participants were taken about half an hour to give their complete responses on the measures and then with thanks data were collected.

\section{Statistical Analysis}

In order to meet the research objective Simple Linear Regression and person product moment correlation was applied.

\section{RESULTS}

Table-1: Represents Pearson Product Moment Correlation analysis between different dimensions of Emotional Maturity and Stress among undergraduate students.

\begin{tabular}{|c|c|c|c|c|c|c|}
\hline \multicolumn{7}{|c|}{ Correlations } \\
\hline & & $\begin{array}{l}\text { Emotional } \\
\text { Stability }\end{array}$ & $\begin{array}{c}\text { Emotional } \\
\text { Progression }\end{array}$ & $\begin{array}{c}\text { Social } \\
\text { Adjustment }\end{array}$ & $\begin{array}{l}\text { Personality } \\
\text { Integration }\end{array}$ & $\begin{array}{c}\text { Independenc } \\
\mathrm{e}\end{array}$ \\
\hline \multirow[t]{3}{*}{ Stress Level } & $\begin{array}{l}\text { Pearson } \\
\text { Correlation }\end{array}$ & $-.267^{* *}$ & $-.173^{*}$ & $-.287^{* *}$ & $-.314^{* *}$ & $-.326^{* *}$ \\
\hline & Sig. (2-tailed) & .001 & .034 & .000 & .000 & .000 \\
\hline & $\mathrm{N}$ & 150 & 150 & 150 & 150 & 150 \\
\hline
\end{tabular}

*. Correlation is significant at the 0.05 level (2-tailed).

${ }^{* *}$. Correlation is significant at the 0.01 level (2-tailed).

Where it was found that Emotional Stability (-.267), Emotional Progression (-.173), Social Adjustment (-.287), Personality Integration (-.314) and Independence (-.326) significantly and negatively correlated with stress level. It means that different dimensions of emotional maturity 
negatively correlated with stress level which indicates that when emotional maturity increases stress level decreases and when emotional maturity decreases stress level increases.

Table-2: Represents Simple Linear Regression analysis, Emotional Maturity as predictor of Stress among undergraduate students.

\begin{tabular}{|l|c|r|r|r|}
\hline \multicolumn{5}{|c|}{ Model Summary } \\
\hline Model & R & R Square & $\begin{array}{c}\text { Adjusted R } \\
\text { Square }\end{array}$ & $\begin{array}{r}\text { Std. Error of } \\
\text { the Estimate }\end{array}$ \\
\hline 1 & $.356^{\mathrm{a}}$ & .127 & .121 & 11.122 \\
\hline \multicolumn{5}{|l|}{ a. Predictors: (Constant), Emotional Maturity } \\
\hline
\end{tabular}

The above table shows the Model Summary indicating one Predictor of the model, in which correlation between Emotional Maturity and Stress was found to be $\mathrm{R}=.356$, and $\mathrm{R}$ Square $=.127$ which indicates the actual contribution of emotional maturity to stress, the real covariance magnitude of Predictor variable to the Criterion Variable came out $12.7 \%$.

Table-3: Showing the Coefficient details of Emotional Maturity and Stress of undergraduate Students.

\begin{tabular}{|c|c|c|c|c|c|c|}
\hline \multicolumn{7}{|c|}{ Coefficients } \\
\hline & & \multicolumn{2}{|c|}{$\begin{array}{l}\text { Unstandardized } \\
\text { Coefficients }\end{array}$} & \multirow{2}{*}{\begin{tabular}{|c} 
Standardized \\
Coefficients
\end{tabular}} & \multirow[b]{2}{*}{$\mathrm{t}$} & \multirow[b]{2}{*}{ Sig. } \\
\hline \multicolumn{2}{|c|}{ Model } & $\mathrm{B}$ & Std. Error & & & \\
\hline \multirow[t]{2}{*}{1} & (Constant) & 46.867 & 4.976 & & 9.418 & .000 \\
\hline & $\begin{array}{l}\text { Emotional } \\
\text { Maturity }\end{array}$ & -.128 & .028 & -.356 & -4.633 & .000 \\
\hline \multicolumn{3}{|c|}{ a. Dependent Variable: Stress Level } & & & & \\
\hline
\end{tabular}

The Value of Beta $=-.356$ which indicates that emotional maturity negatively and significantly correlated with stress among undergraduate Students. It means that when emotional maturity increases stress decreases and when emotional maturity decreases stress increases.

The Statistical value mentioned in the table indicates that $\mathrm{t}=-4.633$ which is significant for emotional maturity and it shows that emotional maturity has its significant impact on stress among undergraduate students. 


\section{DISCUSSION}

Finding shows that all dimensions of emotional maturity i.e. emotional stability, emotional progression, social adjustment, personality integration and independence are negatively correlated with stress. It indicates that when emotional maturity increases stress decreases and when emotional maturity decreases stress increases. Whereas emotional stability refers to the uniqueness of a person that does not allow him to react terribly or noticeable changes in any emotional situation, similarly it also helps individuals to tackle the situation accordingly, which is important for dealing with stressful situations. Coping with critical situations emotional progression plays an important role, because it is a quality of a person that refers to a feeling of tolerable innovation and going through vigor of emotions in relation to the environment to ensure a optimistic thinking fill with morality and contentment. Social adjustment refers to a practice of interaction between the needs of a person and demands of the social environment in any given situation; therefore they can maintain and adjust a desired relationship with environment. As a result, it may be clarify as a person's harmonious relationship with his social world. Personality integration is the process of confidently unifying the diverse elements of an individual's motives and lively tendencies, resulting in harmonious coactions of the inner clash in the fearless expression of behavior (English and English, 1958). There is a general consensus that those who express their views fearless, expected to experience low stress magnitude. Independence is the capacity of a person's attitudinal tendency to be self dependent or of confrontation to manage by others where, he can take his decisions by his own judgment based on facts by utilizing his intellectual and creative potentialities. These virtues also lead toward the selection of best possibilities according to their potential. Who deal with the task that is under his/her assessment they will manage it effectively and their will not be any possibility of involving in critical situation.

\section{CONCLUSION}

Finally, it is concluded that to deal with stress emotional maturity is necessary. The sample of the study was undergraduate students where it was seen that emotional maturity played major role in managing and responding to every actions of life. Consequently, it is concluded that different dimensions of emotional maturity as well as overall emotional maturity significantly and negatively correlated $(-.356>0.01)$ with stress among undergraduate students. It means that who is emotionally mature expected to experience less stress as compare to those who are immature. The persons having emotional maturity are able to self control, feel effectively, socially adjusted, having relational harmony and think independently. Whereas, maturity is the ability to deal with the environment in a proper manner it also helps to tackle critical situations effectively. It is also reported by Wechsler and David (1950) that maturity includes being aware of the appropriate time and place to carry out himself and knowing when to perform. Geeta and Vijayalaxmi (2006) also reported that adolescents with high emotional maturity have better ability of managing, expressing and controlling themselves in every part of actions. 


\section{ACKNOWLEDGEMENTS}

I wish to compensate heartfelt thanks to Dr. Kr Sajid Ali Khan, Associate Professor, Department of Psychology, Aligarh Muslim University, Aligarh for his regular guidance. I also express my thanks to all participants in the study, my colleagues and friends who help me in this portion of research.

\section{REFERENCES}

1. Anjali and Ramanna, (2005). Muddu Makkalannu Apputtiruva Vattada, Vijay Karnataka, Puravani, July 3rd, Sunday, 3.

2. Chamberlain, V.C. (1960) Adolescence to Maturity", London: The Badley Head.

3. Geeta, S. P. \& Vijayalaxmi, A. A., (2006). Karnatak University, Dharwad. Journal of the Indian Academy of Applied Psychology, January, Vol. 32, No.1, 66-70.

4. Hardy, Sally, (1998). Occupational Stress: Personal and Professional Approaches. United Kingdom: Stanley Thornes ltd. pp. 18-43.

5. Latha, S., (1997) Development of Stressful life events Questionnaire Journal of Psychometry 1997, vol 10, No-2.

6. Mangal, S.K., (1984). Abnormal Psychology, Sterling Publication, New Delhi.

7. Wechsler, David (1 March 1950). "Intellectual Development and Psychological Maturity". Child Development 21 (1): 45. doi:10.2307/ 1126418. JSTOR 1126418.

8. Yashvir Singh and Mahesh Bhargana (2005). Manual for Emotional Maturity Score, National Psychological Corporation, India, $1-15$. 